\title{
ANALISIS PERBANDINGAN EXPERIENTIAL VALUE ANTARA HONG TANG DAN BLACK BALL SERTA HUBUNGANNYADENGAN CUSTOMER SATISFACTION
}

\author{
Annetta Gunawan \\ Management Department, School of Business Management, BINUS University \\ Jln. K.H. Syahdan No. 9, Palmerah, Jakarta Barat 11480 \\ annetta_gunawan@hotmail.com
}

\begin{abstract}
Black Ball and Hong Tang are two pioneers of Taiwanese dessert sellers in Jakarta. Both of them have product offering characteristics that are alike and have the same target market. From the initial observation, the researcher found that even though Black Ball has more outlets than Hong Tang, but Black Ball seems to be less popular than Hong Tang. The consumers' preferences are varied, there are some consumers prefer Hong Tang, but there are also those who choose Black Ball, because of the food quality, the service provided, and also the experiences they get during the consumption process. Therefore, both Black Ball and Hong Tang have to consider about the experiential value to be offered to their customers, in order to increase their customer satisfaction, so that they can sustainably survive in the midst of challenging competition. The objectives of this research are to examine whether there is any difference of experiential value dimensions and customer satisfaction between Hong Tang and Black Ball and to examine the relationship between experiential value dimensions and customer satisfaction of Hong Tang and Black Ball. The result of this research concludes that there is no difference of all experiential value dimensions and customer satisfaction between Hong Tang and Black Ball and there is a strong and significant relationship between all experiential value dimensions and customer satisfaction of Hong Tang and Black Ball.
\end{abstract}

Keywords: experiential value, customer satisfaction, Taiwanese dessert restaurant

\begin{abstract}
ABSTRAK
Black Ball dan Hong Tang adalah dua pelopor dalam penyedia Taiwanese dessert di Jakarta. Kedua pemain ini memiliki karakteristik penawaran produk yang hampir sama dan menyasar target market yang sama pula. Dari observasi awal yang dilakukan, peneliti menemukan bahwa walaupun Black Ball memiliki lebih banyak outlet daripada Hong Tang, Black Ball tampaknya masih kalah populer dibanding Hong Tang. Preferensi konsumen bervariasi, ada yang lebih memilih Hong Tang, ada pula yang memilih Black Ball, dengan alasan kualitas makanan, pelayanan yang diberikan, maupun pengalaman yang diperoleh saat mengonsumsi. Untuk itu, Black Ball maupun Hong Tang harus memerhatikan experiential value yang bisa ditawarkan kepada pelanggan dalam rangka meningkatkan customer satisfaction masing-masing, agar dapat bertahan secara berkepanjangan di tengah-tengah persaingan yang makin menantang. Tujuan dari penelitian ini adalah untuk menguji adanya perbedaan dimensi experiential value dan customer satisfaction di antara pelanggan Hong Tang dan Black Ball, serta menguji hubungan antara dimensi experiential value dengan customer satisfaction pada Hong Tang dan Black Ball. Hasil dari penelitian ini menyatakan bahwa tidak ada perbedaan di antara semua dimensi experiential value dan customer satisfaction antara Hong Tang dan Black Ball, serta ada hubungan yang signifikan, kuat, dan searah antara semua dimensi experiential value dengan customer satisfaction.
\end{abstract}

Kata kunci: experiential value, customer satisfaction, Taiwanese dessert restaurant 


\section{PENDAHULUAN}

Saat ini, masyarakat Jakarta lebih sering untuk makan di luar, tidak seperti beberapa dekade yang lalu ketika orang makan di luar hanya di saat-saat spesial. Pilihan restoran juga makin bervariasi, terutama di Jakarta yang masyarakatnya heterogen dan lebih terbuka terhadap hal-hal baru. Hal itu membuat banyak pihak memanfaatkan peluang untuk membuka restoran atau menjual makanan dari berbagai cita rasa dan budaya, salah satunya adalah Taiwanese dessert yang sedang populer di Jakarta akhir-akhir ini.

Black Ball dan Hong Tang adalah 2 pelopor dalam penyedia Taiwanese dessert di Jakarta. Black Ball sampai saat ini adalah satu-satunya Taiwanese dessert yang merupakan franchise dari Taiwan dan Taiwanese dessert house yang memiliki outlet paling banyak di Jakarta, yaitu 11 outlet. Sedangkan Hong Tang yang merupakan pionir dalam penyedia Taiwanese dessert dan berawal dari bisnis keluarga, saat ini memiliki 5 outlet. Kedua pemain ini memiliki karakteristik penawaran produk yang hampir sama dan menyasar target market yang sama pula. Dari observasi awal yang dilakukan, peneliti menemukan bahwa walaupun Black Ball memiliki lebih banyak outlet daripada Hong Tang, tampaknya masih kalah populer dibanding Hong Tang. Preferensi konsumen bervariasi, ada yang lebih memilih Hong Tang, ada pula yang memilih Black Ball, dengan alasan kualitas makanan, pelayanan yang diberikan, maupun pengalaman yang diperoleh saat mengonsumsi.

Masa depan yang menjanjikan bagi industri food and beverages yang ditunjukkan oleh naiknya porsi pengeluaran untuk makanan sebesar 47,71\% pada 2012 (BPS, 2012), menyebabkan ketatnya kompetisi di industri tersebut, termasuk Taiwanese dessert. Beberapa bulan ke belakang, makin banyak kompetitor baru yang bermunculan di pasar Taiwanese dessert di Jakarta. Untuk itu, sebagai 2 pemain pendahulu, Black Ball dan Hong Tang perlu mengeluarkan usaha lebih keras untuk bisa mempertahankan dan bahkan menambah pelanggannya.

Pencapaian customer satisfaction adalah orientasi utama dari segala aktivitas pemasaran yang dilakukan oleh perusahaan. Usaha-usaha pemasaran akan menghasilkan pembelian dan atau konsumsi, yang pada gilirannya akan menyebabkan fenomena pascapembelian seperti perubahan sikap konsumen, pembelian berulang, dan brand loyalty (Lee et al., 2010). Sebagaimana ditambahkan oleh Evans dan Lindsay dalam Mohsan, et al. (2011), bahwa perusahaan yang memiliki pelanggan yang puas dapat memperoleh peluang untuk mengubah para pelanggannya menjadi pelanggan loyal dalam jangka panjang. Untuk itu, pemasar perlu menaruh perhatian yang besar pada pencapaian customer satisfaction untuk dapat memperoleh keuntungan jangka panjang.

Salah satu faktor yang berkontribusi penting bagi pencapaian customer satisfaction adalah experiential value. Pelanggan mempersepsikan experiential value dari berbagai jenis pengalaman yang diperolehnya ketika berinteraksi dengan penyedia jasa (Datta \& Vasantha, 2013). Experiential value yang dirasakan oleh pelanggan dapat menghasilkan nilai ekonomis bagi perusahaan. Seperti disebutkan oleh Slater dalam Woodside, et al. (2008), bahwa menciptakan nilai pelangan yang unggul adalah kunci bagi keberlangsungan dan kesuksesan perusahaan dalam jangka panjang. Hal ini sejalan dengan pendapat Onaran, et. al. (2013) yang menyatakan bahwa dengan menyediakan nilai yang dirasakan pelanggan adalah kunci untuk menciptakan dan mempertahankan hubungan jangka panjang dengan pelanggan dan pada akhirnya akan menyumbang kepada keunggulan kompetitif perusahaan. Dengan demikian, baik Black Ball maupun Hong Tang harus memerhatikan experiential value yang bisa ditawarkan kepada pelanggan masing-masing dalam rangka meningkatkan customer satisfaction. Hal tersebut dilakukan agar mereka dapat bertahan secara berkepanjangan di tengah-tengah persaingan yang makin menantang. 
Berdasarkan uraian, peneliti tertarik untuk meneliti mengenai experiential value dan customer satisfaction dari kedua pemain pionir di pasar Taiwanese dessert. Tujuan pertama dari penelitian ini adalah untuk menguji adanya perbedaan dimensi experiential value di antara pelanggan Hong Tang dan Black Ball. Tujuan kedua adalah untuk menguji adanya perbedaan customer satisfaction antara Hong Tang dan Black Ball. Tujuan terakhir dari penelitian ini adalah untuk menguji hubungan antara dimensi experiential value dengan customer satisfaction pada Hong Tang dan Black Ball. Hasil dari penelitian ini diharapkan dapat menjadi bahan referensi bagi pembaca dan peneliti lain mengenai hubungan antara variabel customer satisfaction dan experiential value, sehingga bisa dilakukan penelitian lebih lanjut mengenai faktor-faktor yang berkontribusi terhadap customer satisfaction. Hasil dari penelitian ini juga diharapkan dapat memberikan manfaat bagi perusahaan terkait dalam industri Taiwanese dessert, khususnya Hong Tang dan Black Ball, untuk dapat meningkatkan experiential value yang ditawarkan kepada konsumen dalam rangka memberikan kepuasan yang lebih baik lagi untuk konsumen.

\section{Tinjauan Literatur}

\section{Experiential Value}

Experiential berasal dari kata experience yang didefinisikan oleh Merriam-Webster Online Dictionary sebagai "practical knowledge, skill, or practice derived from direct observation of or participation in events or in a particular activity". Prahalad dan Ramaswamy dalam Wang dan Lin (2010) menekankan experiential sebagai dasar nilai yang baru dan nilai pasar modern diciptakan oleh interaksi timbal-balik antara konsumen dengan bisnis.

Sedangkan value didefinisikan oleh Soman dan Marandi (2010) sebagai sesuatu yang diperoleh pelanggan sebagai imbalan atas apa yang dikorbankannya. Value bersifat subjektif dan tercipta berdasarkan pertukaran pengalaman yang terjadi dalam proses transaksi atau persepsi individu (Lee dan Overby dalam Maghnati et al., 2012). Peter dan Olson (2010) menyatakan bahwa sebuah value yang dipuaskan biasanya menghasilkan dampak positif (kesenangan, sukacita, kepuasan); sebaliknya sebuah value yang dihalangi menghasilkan dampak negatif (frustasi, kemarahan, kekecewaan).

Maghnati et al. (2012) menyatakan bahwa experiential value dapat diciptakan melalui pengalaman dalam mengkonsumsi produk atau jasa. Literatur marketing saat ini menonjolkan pentingnya service experience dan menyarankan bahwa penyedia jasa tidak cukup hanya menciptakan lingkungan teatrikal (menyediakan kesenangan dan hiburan), tetapi juga harus mendorong pelanggan untuk berpartisipasi dalam service experience (Mathwick et al. dalam Line, 2012).

Park dan Cha (2011) mengadopsi 4 dimensi experiential value sebagai faktor utama dalam memengaruhi kepuasan dan preferensi makan di restoran. Keempat dimensi tersebut adalah: (a) kualitas makanan (food quality), didefinisikan sebagai sebagai fitur sendiri yang dapat dibedakan dari jenis makanan lain, misalnya lezat; (b) keunggulan pelayanan (service excellence), mengacu pada apresiasi umum pelanggan terhadap suatu penyedia jasa yang menunjukkan keahlian dan menyediakan kinerja layanan yang dapat diandalkan; (c) estetika (aesthetics), menggambarkan reaksi terhadap kecocokan dan kesatuan elemen-elemen visual yang disajikan di restoran, misalnya tercermin dalam interior design dan ambience; (5) kesenangan (playfulness), yaitu pengalaman intrinsik yang dirasakan pelanggan untuk mencari kesenangan dan keluar dari rutinitas.

\section{Customer Satisfaction}

Satisfaction berasal dari bahasa Latin satis (cukup) dan facere (melakukan atau membuat). Satisfaction adalah respons konsumen terhadap evaluasi ketidaksesuaian yang dirasakan antara harapan sebelumnya dan kinerja aktual produk yang dirasakan setelah konsumsi. Produk dan layanan 
yang memuaskan memiliki kapasitas untuk menyediakan apa yang dicari sampai ke titik menjadi cukup (Oliver, 2010). Hal tersebut sejalan dengan Grigoroudis dan Siskos (2010) yang menyimpulkan satisfaction sebagai standar bagaimana total produk atau jasa yang ditawarkan memenuhi harapan pelanggan.

Customer satisfaction secara langsung memengaruhi perilaku pasca-pembelian pelanggan, seperti memuji, mengkomplain, menaikkan atau menurunkan loyalty, sikap, dan brand switching (Liu, 2008). Jika konsumen puas dengan suatu produk, jasa, atau brand, mereka akan cenderung terus membelinya dan bahkan memberitahu orang lain tentang pengalaman menyenangkan mereka mengenai produk, jasa, atau brand tersebut. Jika mereka tidak puas, konsumen cenderung akan mengganti pilihan produk, jasa, atau brand, serta menyuarakan komplainnya kepada produsen, penjual, dan konsumen lain (Peter \& Olson, 2010).

Woodside et al. dalam Wang dan Lin (2010) menggambarkan customer satisfaction sebagai suatu sikap setelah proses konsumsi dan menunjukkan tingkat seberapa pelanggan suka atau tidak suka terhadap produk atau jasa setelah pengalaman yang dirasakannya. Jadi, customer satisfaction terjadi ketika harapan pelanggan terpenuhi oleh kinerja layanan yang diterima dari perusahaan.

\section{Hubungan Experiential Value dengan Customer Satisfaction}

$\mathrm{Wu}$ dan Liang (2009) menyimpulkan bahwa experiential value merupakan mediator bagi faktor lingkungan restoran dan interaksi restoran dengan konsumen dalam memengaruhi customer satisfaction secara positif dan tidak langsung. Hal ini sejalan dengan pendapat dari Wang dan Lin (2010) yang menyatakan bahwa jika manajer dapat menemukan faktor-faktor yang memengaruhi customer satisfaction terhadap produk atau jasa, perusahaan dapat mengubah pengalaman pelanggan ketika menggunakan produk atau jasa tersebut sehingga pelanggan memperoleh kepuasan maksimum. Dengan kata lain, penciptaan experiential value yang lebih baik dapat memengaruhi pelanggan dalam menghasilkan kepuasan yang positif.

Datta dan Vasantha (2013) menambahkan, experiential value yang dirasakan oleh pelanggan dapat menyebabkan kepuasan pelanggan. Sehingga pada akhirnya experiential value dan customer satisfaction akan secara bersama-sama menciptakan pelanggan yang loyal. Pendapat tersebut didukung oleh Keng et al. (2007) yang menyimpulkan bahwa semua dimensi dari experiential value secara positif memengaruhi intensi perilaku pelanggan.

\section{METODE}

Penelitian ini merupakan penelitian asosiatif dan komparatif. Sampel yang diambil dalam penelitian ini sebanyak 110 orang responden, yang terdiri dari 55 orang pelanggan Hong Tang dan 55 orang pelanggan Black Ball. Dalam mengumpulkan data, penelitian menggunakan kuesioner yang disebar secara random dengan menggunakan graphic rating scale untuk mengukur variabel-variabel dalam penelitian dengan diberikan bobot 1 sampai dengan 10. Bobot 1 adalah nilai paling rendah dan bobot 10 adalah nilai paling tinggi. Variabel-variabel dalam penelitian ini dapat dioperasionalkan dalam Tabel 1 berikut. 
Tabel 1 Operasionalisasi Variabel

\begin{tabular}{llll}
\hline \multicolumn{1}{c}{ Variabel } & \multicolumn{1}{c}{ Dimensi } & \multicolumn{1}{c}{ Indikator } & Skala \\
\hline Experiential Value $(\mathbf{X})$ & Kualitas Makanan & $\begin{array}{l}\text { Jenis-jenis dessert yang disajikan terasa lezat dan } \\
\text { berkualitas baik }\end{array}$ & Ordinal \\
\cline { 2 - 5 } & Keunggulan Pelayanan & $\begin{array}{l}\text { Pramusaji dapat melayani pelanggan dengan baik } \\
\text { Ordinal }\end{array}$ & Ordinal \\
\cline { 2 - 5 } & Estetika & Suasana restoran dessert dedesain secara menarik & Mengunjungi restoran dessert merupakan aktivitas \\
& Kesenangan & $\begin{array}{l}\text { hiburan yang dapat memberikan kesenangan bagi } \\
\text { pelanggan }\end{array}$ & Ordinal \\
\hline Customer Satisfaction (Y) & Kepuasan Pelanggan & $\begin{array}{l}\text { Pelanggan merasa bahwa nilai produk dan } \\
\text { pelayanan yang diterimanya dari restoran dessert } \\
\text { sesuai dengan yang diharapkannya }\end{array}$ & Ordinal \\
\hline
\end{tabular}

Hipotesis dalam penelitian ini adalah sebagai berikut.

Untuk Tujuan Pertama

$\mathrm{Ho}_{1}=$ Tidak ada perbedaan persepsi pelanggan mengenai kualitas makanan antara Hong Tang dan Black Ball

$\mathrm{Ha}_{1}=$ Ada perbedaan persepsi pelanggan mengenai kualitas makanan antara Hong Tang dan Black Ball

$\mathrm{Ho}_{2}=$ Tidak ada perbedaan persepsi pelanggan mengenai keunggulan pelayanan antara Hong Tang dan Black Ball

$\mathrm{Ha}_{2}=$ Ada perbedaan persepsi pelanggan mengenai keunggulan pelayanan antara Hong Tang dan Black Ball

$\mathrm{Ho}_{3}=$ Tidak ada perbedaan persepsi pelanggan mengenai estetika antara Hong Tang dan Black Ball

$\mathrm{Ha}_{3}=$ Ada perbedaan persepsi pelanggan mengenai estetika antara Hong Tang dan Black Ball

$\mathrm{Ho}_{4}=$ Tidak ada perbedaan persepsi pelanggan mengenai kesenangan antara Hong Tang dan Black Ball

$\mathrm{Ha}_{4}=$ Ada perbedaan persepsi pelanggan mengenai kesenangan antara Hong Tang dan Black Ball

Untuk Tujuan Kedua

Ho $=$ Tidak ada perbedaan customer satisfaction antara Hong Tang dan Black Ball

$\mathrm{Ha}=$ Ada perbedaan customer satisfaction antara Hong Tang dan Black Ball

Untuk Tujuan Ketiga

$\mathrm{Ho}_{1}=$ Tidak ada hubungan yang signifikan antara persepsi pelanggan mengenai kualitas makanan dengan customer satisfaction pada Hong Tang dan Black Ball

$\mathrm{Ha}_{1}=$ Ada hubungan yang signifikan antara persepsi pelanggan mengenai kualitas makanan dengan customer satisfaction pada Hong Tang dan Black Ball

$\mathrm{Ho}_{2}=$ Tidak ada hubungan yang signifikan antara persepsi pelanggan mengenai keunggulan pelayanan dengan customer satisfaction pada Hong Tang dan Black Ball

$\mathrm{Ha}_{2}=$ Ada hubungan yang signifikan antara persepsi pelanggan mengenai keunggulan pelayanan dengan customer satisfaction pada Hong Tang dan Black Ball

$\mathrm{Ho}_{3}=$ Tidak ada hubungan yang signifikan antara persepsi pelanggan mengenai estetika dengan customer satisfaction pada Hong Tang dan Black Ball

$\mathrm{Ha}_{3}=$ Ada hubungan yang signifikan antara persepsi pelanggan mengenai estetika dengan customer satisfaction pada Hong Tang dan Black Ball

$\mathrm{Ho}_{4}=$ Tidak ada hubungan yang signifikan antara persepsi pelanggan mengenai kesenangan dengan customer satisfaction pada Hong Tang dan Black Ball

$\mathrm{Ha}_{4}=$ Ada hubungan yang signifikan antara persepsi pelanggan mengenai kesenangan dengan customer satisfaction pada Hong Tang dan Black Ball 


\section{HASIL DAN PEMBAHASAN}

Karena data berdistribusi bebas dan memiliki skala ordinal, metode nonmetrik digunakan. Untuk menganalisis data, uji Mann-Whitney dan Korelasi Kendall dilakukan untuk menjawab tujuantujuan penelitian. Rata-rata skor tiap variabel disajikan pada Tabel 2 berikut.

Tabel 2 Rata-rata Skor Tiap Variabel

\begin{tabular}{lcc}
\hline \multicolumn{1}{c}{ Variabel } & Rata-rata Hong Tang & Rata-rata Black Ball \\
\hline Kualitas makanan (x1) & 6.38 & 6.40 \\
Keunggulan pelayanan (x2) & 5.87 & 5.91 \\
Estetika (x3) & 5.49 & 5.64 \\
Kesenangan (x4) & 5.47 & 5.13 \\
Customer satisfaction (y) & 6.09 & 5.75 \\
\hline
\end{tabular}

Dari Tabel 2 dapat dilihat bahwa secara keseluruhan tidak terdapat perbedaan yang terlalu mencolok di antara Hong Tang dan Black Ball dalam hal experiential value dan customer satisfaction. Nilai rata-rata variabel dari keduanya berkisar antara skala $5-6$ dari skala tertinggi 10 . Nilai tersebut menandakan bahwa experiential value yang dipersepsikan pelanggan dan customer satisfaction tidak termasuk buruk, tetapi juga tidak terlalu unggul. Meskipun begitu, Hong Tang lebih baik daripada Black Ball dalam hal kesenangan. Sedangkan Black Ball lebih unggul dalam hal kualitas makanan, pelayanan, dan estetika dengan selisih yang sangat tipis. Akan tetapi, customer satisfaction Hong Tang yang lebih tinggi. Ini berarti, terhadap nilai yang ditawarkan, pelanggan Hong Tang merasa harapan mereka lebih terpenuhi daripada pelanggan Black Ball. Hal ini mungkin disebabkan Black Ball merupakan gerai franchise dari Taiwan langsung, sehingga pelanggan memiliki harapan performa Black Ball seharusnya lebih tinggi daripada kompetitor lainnya yang berasal dari dalam negeri. Sebaliknya, Hong Tang yang berawal dari bisnis keluarga lebih bisa untuk memenuhi harapan pelanggannya.

\section{Uji Mann-Whitney}

Hasil pengolahan data penelitian dengan metode Mann-Whitney Test adalah seperti gambar tabel sebagai berikut.

Tabel 3 Hasil Uji Mann-Whitney

\begin{tabular}{|c|c|c|c|c|c|}
\hline & $\times 1$ & $\times 2$ & $\times 3$ & $\times 4$ & $y$ \\
\hline Mann-Whitney U & $1.508 \mathrm{E} 3$ & $1.494 \mathrm{E} 3$ & $1.487 \mathrm{E} 3$ & $1.332 \mathrm{E} 3$ & $1.350 \mathrm{E} 3$ \\
\hline Wilcoxon W & $3.048 E 3$ & $3.034 \mathrm{E} 3$ & $3.027 \mathrm{E} 3$ & $2.872 \mathrm{E} 3$ & $2.890 \mathrm{E} 3$ \\
\hline$z$ & -.027 & -.109 & -.154 & -1.089 & -.979 \\
\hline Asymp. Sig. (2-tailed) & .978 & .913 & .878 & .276 & .328 \\
\hline
\end{tabular}

Untuk Tujuan Pertama

Hasil Hipotesis 1

Sig $=0.978 / 2=0.489>0.05 \rightarrow$ Ho diterima, sehingga tidak ada perbedaan persepsi pelanggan mengenai kualitas makanan (x1) antara Hong Tang dan Black Ball

Hasil Hipotesis 2

Sig $=0.913 / 2=0.457>0.05 \rightarrow$ Ho diterima, sehingga tidak ada perbedaan persepsi pelanggan mengenai keunggulan pelayanan (x2) antara Hong Tang dan Black Ball 
Hasil Hipotesis 3

Sig $=0.878 / 2=0.439>0.05 \rightarrow$ Ho diterima, sehingga tidak ada perbedaan persepsi pelanggan mengenai estetika (x3) antara Hong Tang dan Black Ball

Hasil Hipotesis 4

Sig $=0.276 / 2=0.138>0.05 \rightarrow$ Ho diterima, sehingga tidak ada perbedaan persepsi pelanggan mengenai kesenangan (x4) antara Hong Tang dan Black Ball

Untuk Tujuan Kedua

Hasil Hipotesis

Sig $=0.328 / 2=0.164>0.05 \rightarrow$ Ho diterima, sehingga tidak ada perbedaan persepsi pelanggan mengenai kualitas makanan (x1) antara Hong Tang dan Black Ball

Hasil pengujian Mann-Whitney menunjukkan bahwa secara keseluruhan tidak ada perbedaan yang signifikan dari kelima variabel yang diteliti antara kedua pionir Taiwanese Dessert di Jakarta, yaitu Hong Tang dan Black Ball. Penting bagi perusahaan untuk mencapai dan mempertahankan kepuasan pelanggannya karena pelanggan yang puas akan menunjukkan loyalitas dan menyebarkan word-of-mouth yang positif (Kim, et. al., 2006). Dari segi kualitas makanan, memang kedua pemain ini menyajikan menu yang bahan bakunya hampir serupa, dan sama-sama variatif, hanya berbeda kombinasi dan bahan tambahan saja. Walaupun Hong Tang bukan franchise dari Taiwan langsung, kualitas dan rasa produknya tidak kalah dari Black Ball. Pelayanan yang diberikan pun dirasakan setara oleh pelanggan keduanya, baik dari keramahan pelayan, kecepatan pelayanan, maupun pengetahuan pelayan mengenai produk. Demikian pula dengan estetika atau desain outlet dan suasana yang ditawarkan, keduanya hampir serupa: memiliki tempat yang tidak terlalu luas dan tidak terlalu banyak menampung pengunjung, sehingga tidak jarang pengunjung harus mengantre terlebih dahulu. Masing-masing memiliki desain dengan nuansa Taiwanese street. Setiap outlet didesain secara berbeda tetapi tetap menonjolkan ciri khas Hong Tang dan Black Ball. Dimensi kesenangan juga dipersepsikan tidak berbeda oleh pelanggan di antara keduanya, yang memang pelanggan biasanya mengunjungi Taiwanese dessert house sebagai salah satu hiburan kuliner bukan untuk makanan utama. Hal tersebut tercermin dari strategi lokasi keduanya yang biasanya terletak di mal atau di kawasan penjual makanan berkumpul.

Persaingan yang ketat dan masih terus akan berlangsung ditunjukkan oleh kedua pionir ini. Tingkat customer satisfaction di antara keduanya tidak berbeda secara signifikan. Hong Tang mulai mengejar Black Ball dalam hal jumlah outlet. Hal itu dapat terlihat dari gencarnya ekspansi outletoutlet baru yang dibuka Hong Tang yang tadinya berawal bukan dari mal, sekarang mulai merajalela di mal-mal Jakarta.

\section{Uji Korelasi Kendall}

Hasil pengolahan data penelitian dengan metode korelasi Kendall adalah sebagai berikut.

Tabel 4 Hasil Uji Korelasi Kendall

\begin{tabular}{|c|c|c|c|c|c|c|c|}
\hline & & & $y$ & $\times 1$ & $\times 2$ & $\times 3$ & $\times 4$ \\
\hline \multirow[t]{7}{*}{ Kendall's tau_b } & 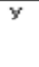 & $\begin{array}{l}\text { Correlation Coefficient } \\
\text { Sig. (2-tailed) } \\
\mathrm{N}\end{array}$ & $\begin{array}{r}1.000 \\
110\end{array}$ & $\begin{array}{r}.717 \\
.000 \\
110\end{array}$ & $\begin{array}{l}.705 \\
.000 \\
110\end{array}$ & $\begin{array}{l}.669 \\
.000 \\
110\end{array}$ & $\begin{array}{l}.718 \\
.000 \\
110\end{array}$ \\
\hline & $\times 1$ & Correlation Coefficient & .717 & 1.000 & $\begin{array}{l}170 \\
.641\end{array}$ & $\begin{array}{l}170 \\
.596\end{array}$ & .621 \\
\hline & & $\begin{array}{l}\text { Sig. (2-tailed) } \\
N\end{array}$ & $\begin{array}{r}.000 \\
110\end{array}$ & 110 & .000 & .000 & .000 \\
\hline & $\times 2$ & $\begin{array}{l}\text { Correlation Coefficient } \\
\text { Sig. (2-tailed) } \\
\mathrm{N}\end{array}$ & $\begin{array}{l}.705 \\
.000 \\
110\end{array}$ & $\begin{array}{r}.641 \\
.000 \\
110\end{array}$ & $\begin{array}{r}1.000 \\
110\end{array}$ & $\begin{array}{l}.641 \\
.000 \\
110\end{array}$ & $\begin{array}{l}.638 \\
.000 \\
110\end{array}$ \\
\hline & $\times 3$ & $\begin{array}{l}\text { Correlation Coefficient } \\
\text { Sig. (2-tailed) }\end{array}$ & $\begin{array}{l}.669 \\
.000\end{array}$ & $\begin{array}{l}.596 \\
.000\end{array}$ & $\begin{array}{l}.641 \\
.000\end{array}$ & 1.000 & $\begin{array}{l}.622 \\
.000\end{array}$ \\
\hline & & $\mathrm{N}$ & 110 & 110 & 110 & 110 & 110 \\
\hline & $\times 4$ & $\begin{array}{l}\text { Correlation Coefficient } \\
\text { Sig. (2-tailed) } \\
\text { N }\end{array}$ & $\begin{array}{l}.718 \\
.000 \\
110\end{array}$ & $\begin{array}{l}.621 \\
.000 \\
110\end{array}$ & $\begin{array}{l}.638 \\
.000 \\
110\end{array}$ & .622 & 1.000 \\
\hline
\end{tabular}


Untuk Tujuan Ketiga

Hasil Hipotesis 1

Sig $=0.000<0.05 \rightarrow$ Ho ditolak, sehingga ada hubungan yang signifikan antara persepsi pelanggan mengenai kualitas makanan (x1) dengan customer satisfaction (y) pada Hong Tang dan Black Ball, dengan sifat hubungan kuat dan searah ( $\mathrm{r}=0,717)$.

Hasil Hipotesis 2

Sig $=0.000<0.05 \rightarrow$ Ho ditolak, sehingga ada hubungan yang signifikan antara persepsi pelanggan mengenai keunggulan pelayanan (x2) mengenai kualitas makanan dengan customer satisfaction (y) pada Hong Tang dan Black Ball, dengan sifat hubungan kuat dan searah $(\mathrm{r}=0,705)$.

Hasil Hipotesis 3

Sig $=0.000<0.05 \rightarrow$ Ho ditolak, sehingga ada hubungan yang signifikan antara persepsi pelanggan mengenai estetika (x3) dengan customer satisfaction (y) pada Hong Tang dan Black Ball, dengan sifat hubungan kuat dan searah $(\mathrm{r}=0,669)$.

Hasil Hipotesis 4

Sig $=0.000<0.05 \rightarrow$ Ho ditolak, sehingga ada hubungan yang signifikan antara persepsi pelanggan mengenai kesenangan (x4) dengan customer satisfaction (y) pada Hong Tang dan Black Ball, dengan sifat hubungan kuat dan searah $(\mathrm{r}=0,718)$.

Secara keseluruhan, semua dimensi experiential value memiliki korelasi yang kuat dengan customer satisfaction pada Hong Tang dan Black Ball. Hal ini sejalan dengan pendapat dari Cronin et.al. (2000) bahwa nilai yang diperoleh pelanggan berdasarkan pengalamannya ketika berinteraksi dengan penyedia jasa, yaitu experiential value, memengaruhi customer satisfaction.

Berdasarkan hasil tersebut, baik Hong Tang dan Black Ball harus terus berusaha untuk meningkatkan performa dari masing-masing dimensi experiential value, yang menurut penelitian ini masih dinilai belum terlalu unggul oleh pelanggan. Kualitas makanan dapat ditingkatkan dengan menambah variasi menu atau bahkan menambah variasi bahan baku yang digunakan karena dalam industri makanan pelanggan memang selalu mencari inovasi menu baru untuk mengurangi kejenuhan. Pelayanan dari keduanya pun harus lebih ditingkatkan, yang dari observasi awal yang dilakukan, terdapat beberapa keluhan dari pelanggan mengenai waktu pelayanan yang kurang cepat, baik dari Hong Tang maupun Black Ball. Estetika atau suasana dan desain outlet juga memerlukan pengembangan terus-menerus, apalagi akhir-akhir ini semakin banyak kompetitor baru yang menawarkan keunikan ambience masing-masing. Jika kedua pionir ini tidak melakukan inovasi baru, termasuk dalam hal estetika, mereka akan tertinggal oleh pemain-pemain baru. Terakhir, pelanggan mencari kesenangan atau hiburan ketika mengunjungi Taiwanese dessert house, sehingga Hong Tang dan Black Ball perlu menaruh perhatian untuk memosisikan brand sebagai pemuas kebutuhan rekreasi bagi pelanggan yang ingin refreshing dari rutinitas sehari-hari, yang bisa diusahakan melalui tambahan fitur pelayanan yang bersifat atraktif maupun dengan beragam event atau kontes yang mungkin bisa dilakukan secara periodik untuk dapat mempertahankan segi kesenangan pelanggan.

\section{SIMPULAN}

Simpulan yang diambil dari penelitian ini adalah tidak terdapat perbedaan yang signifikan dari kelima dimensi experiential value, yaitu kualitas makanan, keunggulan pelayanan, estetika, dan kesenangan, serta customer satisfaction di antara Hong Tang dan Black Ball. Lalu, terdapat hubungan yang signifikan di antara kelima dimensi experiential value dengan customer satisfaction pada Hong Tang dan Black Ball. Dengan demikian, kedua pionir dalam industri Taiwanese dessert tersebut harus melakukan usaha-usaha peningkatan experiential value dari para pelanggan, sehingga memperoleh customer satisfaction yang lebih tinggi untuk bertahan dan bahkan tetap unggul dalam persaingan yang ada. 


\section{DAFTAR PUSTAKA}

Ariel, J. (2013, 20 Oktober). Hong Tang vs Black Ball. Diakses 28 Mei 2014 dari http://thetasteexplorer.blogspot.com

BPS. (2012). Indonesia National Socio Economic Survey. Diakses 28 Mei 2014 dari http://www.bps.go.id.

Cronin, J. J., Brady, M. K., \& Hult, G. T. M. (2000). Assessing The Effects of Quality, Value, and Customer Satisfaction on Consumer Behavioral Intentions in Service Environments. Journal of Retailing, 76(2), 193-218.

Datta, V. \& Vasantha, S. (2013). Experiential value, customer satisfaction and customer loyalty: an empirical study of KFC in Chennai. Indian Journal of Applied Research, 3(9), 334-337.

Grigoroudis, E., \& Siskos, Y. (2010). Customer Satisfaction Evaluation: Methods for Measuring and Implementing Service Quality. New York: Springer.

Ivy. (2014, 8 Januari). Jakarta's Taiwanese Dessert Cafes. Diakses 28 Mei 2014 dari http://onlylivy.blogspot.com/2014/01/jakartas-taiwanese-dessert-cafes.html.

Keng, Ching-Jui, et al. (2007). Modeling Service Encounters and Customer Experiential Value in Retailing: An Empirical Investigation of Shopping Mall Customers in Taiwan. International Journal of Service Industry Management, 18(4, pp.349 - 367

Kim, W. G., Lee, Y. K., \& Yoo, Y. J. (2006). Predictors of relationship quality and relationship outcomes in luxury restaurants. Journal of Hospitality \& Tourism Research, 30(2), 143-169.

Lee, S., et al. (2010). A brand loyalty model utilizing team identification and customer satisfaction in the licensed sport product industry. Journal of Research, 5(1), 60-67.

Line, N. (2012). Experiential value, relationship quality, and customer loyalty in full-service restaurants: the moderating role of gender. Journal of Hospitality Marketing \& Management, 22(7), 679-700.

Liu, Y. C. (2008). An Analysis Service Quality, Customer Satisfaction and Customer Loyalty of Commercial Swin Clubs in Taiwan. ProQuest LLC.

Maghnati, F., et al. (2012). Exploring the relationship between experiential marketing and experiential value in the smartphone industry. International Business Research, 5(11), 169-177.

May, A. (2013, 27 September). Hong Tang vs Black Ball. Diakses 28 Mei 2014 dari http://crushingonfood.blogspot.com/2013/09/hongtang-vs-blackball.html.

Merriam-Webster (online). (2014). Diakses 28 Mei 2014 dari http://www.merriamwebster.com/dictionary.

Mohsan, F., et al. (2011). Impact of customer satisfaction on customer loyalty and intentions to switch: evidence from banking sector of Pakistan. International Journal of Business and Social Science, 2(16), 263-270. 
Onaran, B., et al. (2013). A study to investigate the effect of customer value on customer satisfaction, brand loyalty and customer relationship management performance. Business and Economics Research Journal, 4(2), 37-53.

Oliver, R. L. (2010). Satisfaction: A Behavioral Perspective on the Consumer. USA: M.E. Sharpc.

Openrice. (2014). Taiwanese Dessert: BlackBall atau Hong Tang? Diakses 28 Mei 2014 dari http://id.openrice.com.

Park, H., \& Cha, J. (2011). Identifying perceived attributes of Japanese restaurants. Hospitality Administration and Management.

Peter, J. P. \& Olson, J. C. (2010). Consumer Behavior and Marketing Strategy. Singapore: McGrawHill Education.

Soman, D \& Marandi, S. (2010). Managing Customer Value: One Stage at a Time. Singapore: World Scientific.

Wang, C. Y. \& Lin, C. H. (2010). A study of TV drama on relationships among tourists' experiental marketing, experiental value, and satisfaction. The International Journal of Organizational Innovation, 2(3).

Woodside, A. G., Golfetto, F., \& Gibbert, M. (2008). Creating and Managing Superior Customer Value. UK: Emerald.

Wu, C. H. \& Liang, R. (2009). Effect of experiential value on customer satisfaction with service encounters in luxury hotel restaurants. International Journal of Hospitality Management, 28(4), 586-593. 